\title{
We need a renewed focus on primary prevention to tackle youth knife violence
}

\author{
We should focus on working with families, schools, communities, and other organisations to protect \\ our young people from becoming embroiled in violent crime
}

\section{Ruth Ponsford research fellow in school health interventions, Claire Thompson assistant professor, Sara Paparini honorary research fellow}

London School of Hygiene and Tropical Medicine, UK

\begin{abstract}
A recent spate of youth-on-youth stabbings has prompted renewed public and policy interest in the problem of youth violence in England. Although rates fluctuate, police recorded data for England and Wales to March 2018 showed the highest number of offences involving knives or sharp instruments since 2011, and the highest number of sharp instrument homicides since the Home Office Index began in 1946. NHS data for hospitals in England for 2017-18, which include incidents not reported to the police, showed a $15 \%$ increase on the previous year in admissions for assault with a knife or sharp instrument.

Young men are more likely to be the victims and perpetrators of knife crime. Those stabbed to death and those convicted of killings are predominantly male and aged 16-24, and in London around half of victims of knife crime resulting in injury are under the age of 24 .
\end{abstract}

Globally, there have been longstanding calls to take a public health stance to tackling violence of this kind. In principle, such an approach involves treating violence as a disease: quantifying and monitoring it, identifying drivers and risk factors, and using evidence based approaches to stem its spread and to tackle the conditions from which it emerges and propagates.

This shifts attention away from seeing violence solely as a criminal justice problem amenable to a criminal justice solution, to understanding it as a condition that requires more complex responses. These involve whole system, multi-agency synergies between criminal justice systems, schools, healthcare services, industry, third sector organisations, and communities that focus on primary prevention at a population level as well as treat the symptoms of the disease. Such an emphasis is embedded in recent government strategies, including the London mayor's strategy on knife crime and the Home Office serious violence strategy.

Yet, to date, the dominant public policy conversation has remained focused on improving policing strategies and "securitising" neighbourhoods where there is perceived to be a high risk of knife crime. Press and politicians have, for example, linked recent cuts in police funding directly to rises in youth knife crime and have called for increased police visibility, increased police funding, more stop and search operations and powers-including the use of Section 60, allowing the police to stop and search without suspicion within a defined area and time period - the use of knife crime prevention orders for children as young as 12 , and the possible mobilisation of armed patrols in response to outbreaks of violence. In March, the government announced an extra $£ 100 \mathrm{~m}(€ 116 \mathrm{~m}$; \$131m) for police forces in England and Wales "to pay for additional overtime targeted specifically on knife crime." But while policing is inevitably part of the solution, as Camden's youth MP told the House of Commons in November last year, the government "cannot police themselves out of knife crime."

As Britain's home secretary Sajid Javid reduces funding for support programmes for youths affected by and at risk of knife crime, the critical importance of prevention (primary, secondary, and tertiary) as part of a longer term strategy must remain part of the wider public and policy conversation about how to tackle the problem. While the quality of the UK evidence on what works to prevent youth violence remains relatively poor, the international evidence-although disparate and often not well synthesised-indicates that both family and school based interventions show promise. ${ }^{1-4}$ Nonetheless, much of the relevant literature still does not explicitly measure violence outcomes and the evidence on the effectiveness of diversionary, community, and emergency care interventions, for example, is much more limited. ${ }^{5}$ As public health researchers and practitioners, we must continue to build the evidence base by carrying out and reporting on robust evaluation studies. Investing in good quality development work to ensure we are implementing and testing the best possible interventions is key to promoting impact and cost effectiveness.

Alongside the identification of discrete behavioural change programmes, we must also take account of, and invest in interventions that tackle, the wider upstream determinants of youth violence. Perpetration is linked to a range of risk factors, most (though not all) stemming from conditions of 
socioeconomic disadvantage. The association between higher rates of inequality and higher rates of violence is well documented. ${ }^{6}$ Yet the growing rates of inequality in the UK-exacerbated by a decade of austerity resulting in cuts to public services that directly and indirectly affect children and young people-remains conspicuously absent in recent discussions of youth knife crime. Re-focusing attention on tackling the underlying exclusion, poverty, and disadvantage that drives youth violence must be a priority.

And just as patient engagement is crucial to improving health and wellbeing across the population, seeking meaningful community participation to find solutions to serious violence is also necessary. Communities must have a say in how problems most affecting them should be tackled. This is critical since such knowledge can usefully challenge the way "experts" characterise and consequently seek to tackle problems, and help foster appropriate bottom-up solutions that are more likely to be accepted and sustained by communities. ${ }^{7}$

Currently, the public and policy conversation remains fixed on policing and criminal justice solutions when we should also be working with families, schools, communities, and other organisations to, in public health terms, immunise, protect, and rescue our young people from becoming embroiled in violent crime. Simultaneously, we need to be advocating policy solutions that redress the social and material inequalities that drive youth violence. Such an approach takes an explicitly public health stance on the matter-prioritising primary prevention and reducing inequalities alongside policing.

Competing interests: the authors declare no competing interests

Not commissioned, not peer reviewed.

1 Matjasko JL, Vivolo-Kantor AM, Massetti GM, Holland KM, Holt MK, Cruz JD. A systematic meta-review of evaluations of youth violence prevention programs: Common and divergent findings from 25 years of meta-analyses and systematic reviews. Aggress Violent Behav 2012;17:540-52. 10.1016/j.avb.2012.06.006 29503594

2 Farrington D, Gaffney H, Lösel F, Ttofi M. Systematic reviews of the effectiveness of developmental prevention programs in reducing delinquency, aggression, and bullying. Aggress Violent Behav 2017;33:91-10610.1016/j.avb.2016.11.003

3 WHO. Preventing youth violence: An overview of the evidence. 2015. https://apps.who. int/iris/bitstream/handle/10665/181008/9789241509251_eng.pdf; jessionid=AAF051BA263F51193862401B50DCE602? sequence $=1$.

4 Bonell $\mathrm{C}$, Wells $\mathrm{H}$, Harden A, et al. The effects on student health of interventions modifying the school environment: systematic review. J Epidemiol Community Health 2013;67:677-81 10.1136/jech-2012-202247 23682106

5 Melendez-Torres GJ, Dickson K, Fletcher A, et al. Systematic review and meta-analysis of effects of community-delivered positive youth development interventions on violence outcomes. J Epidemiol Community Health 2016;70:1171-7. 10.1136/jech-2015-206132 27445348

6 Wilkinson $\mathrm{R}$. Why is violence more common where inequality is greater? Ann N Y Acad Sci 2004;1036:1-12. 10.1196/annals. 1330.00115817728

7 Popay J. What will it take to get the evidential value of lay knowledge recognised? Int $J$ Public Health 2018;63:1013-4. 10.1007/s00038-018-1145-z 30046850

Published by the BMJ Publishing Group Limited. For permission to use (where not already granted under a licence) please go to http://group.bmj.com/group/rights-licensing/ permissions 